\title{
The Influence of RMB Appreciation on China's Exporters' Investment Decision
}

\author{
Qiu Qi ${ }^{1, a}$ \\ 'Zhejiang University of Commerce and Industry Hangzhou Business School, \\ Tonglu, Hangzhou, Zhejiang, China \\ afangjiaqi64195@163.com
}

Keywords: RMB appreciation; exporters; investment decisions; impact.

\begin{abstract}
In the more than 40 years after the reform and opening up, the Chinese economy has maintained a high-speed growth trend, which has also led to an ever-increasing degree of integration between China and the world economy. China has become an inseparable part of the world economic system, and Chinese goods are sold at a reasonable price. Inexpensive and high quality has become the first choice for importation in many countries. Chinese enterprises have obtained a lot of profits in the process of product export, and also provided strong support for the transformation and upgrading of enterprises. In recent years, the number of Chinese exporters has rapidly increased, and the scale of investment and the scope of investment have undergone tremendous changes. The change in the exchange rate of the RMB has had a very direct impact on China's international trade industry, directly affecting the success or failure of exporters' investment. This has also caused the decision of export investors to undergo tremendous changes in the context of RMB appreciation. This study mainly focuses on the impact of the appreciation of the renminbi on China's export-investors, and hopes to effectively guide investment decisions of investors and create a good environment for the improvement of the core competitiveness of Chinese enterprises.
\end{abstract}

\section{人民币升值对我国出口商投资决策的影响分析}

\author{
邱琪 $1, a$ \\ 1浙江工商大学杭州商学院, 桐庐, 杭州, 浙江, 中国 \\ afangjiaqi64195@163.com
}

关键词：人民币升值；出口商；投资决策；影响

中文摘要. 在改革开放后的四十多年中, 中国经济保持了高速增长态势, 这也使得中国与世 界经济融合的程度不断提升, 我国已经成为世界经济体系中不可分割的部分, 而中国商品以 物美价廉质优成为很多国家进口的首选, 中国企业在产品出口过程中获得了大量的利润, 同 时也为企业的转型升级提供了有力支持。近年来中国出口商数量快速增加，投资规模和投资 范围都发生了巨大变化。人民币汇率的变化对我国国际贸易行业产生了非常直接的影响, 最 终影响到出口商投资的成败，这也使得出口投资商的决策在人民币升值的大背景下发生了巨 大变化。本次研究主要围绕人民币升值对我国出口投资商决策的影响展开分析, 希望有效引 导投资商的投资决策，为我国企业核心竞争力的提升创造良好环境。 


\section{1. 引言}

我国已经成为世界第二大经济体，消费额、人均GDP、综合国力都呈现持续发展状态，中 国在改革开放之初主要以吸引外资为主要目标, 而中国产品的工农业产品在世界范围内具有 很强的竞争优势, 特别是中国相对低廉的人工成本使得中国制造的优势更加明显, 我国出口 商数量不断增加, 大量企业将投资和生产经营重点集中于对外出口领域。而随着一带一路战 略的推进与我国企业转型升级的全面开展, 中国经济发展进入了全新的发展阶段。人民币升 值与人民币国际化进程中，出口企业发挥着极为重要的作用，但投资商也因此面临着更大的 风险, 投资商应该借助这个宝贵契机充分发挥自身优势, 在投资决策方面做出更加准确地判 断，为企业自身发展与国家经济发展做出贡献。

\section{2. 人民币升值的历史沿革}

中国在建国之初实行计划经济制度，而在改革开放政策执行后，中国开始全面推进市场 化经济体制, 这也使得人民币汇率机制在过去几十年间经历逐渐成熟与完善的历程。特别是 在改革开放初期，人民币汇率受到政府政策的显著影响，而在经历汇率制度改革后，人民币 的汇率也逐渐呈现更具有活力与弹性的状态。下图展现了人民币与美元在不同时间段下的汇 率变化情况:

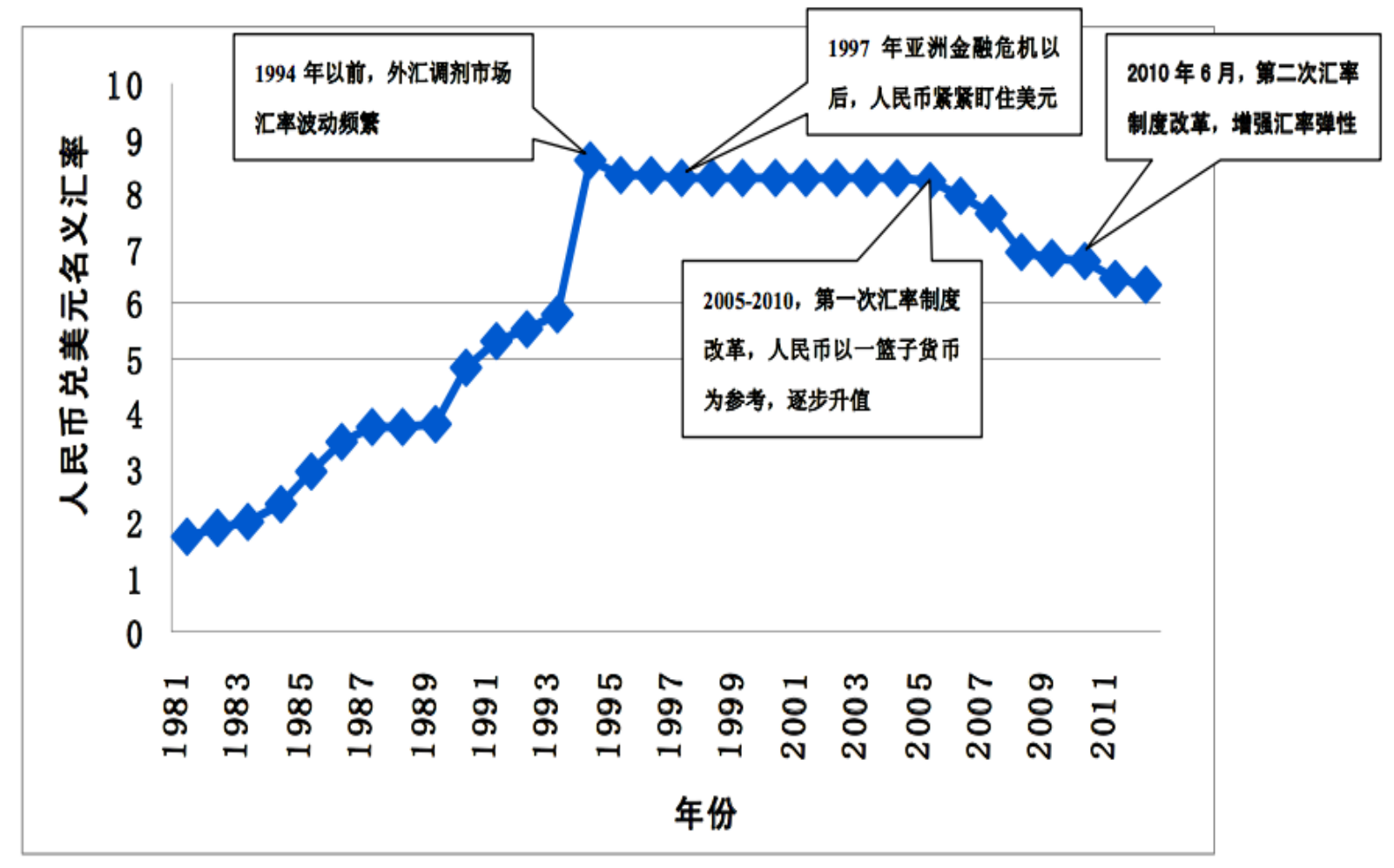

图1.20世纪80年代至21世纪初期的人民币名义汇率走势图

在建国初中，国内对于外汇保持了统一管控的政策，国家对所有外汇进行了行政化管理， 这也导致人民币汇率在国内外存在明显的差异性, 官方汇率无法真实体现人民币的汇率情况。 而在1973年至1993年之间，随着国外货币体系的变化和国内经济政策的变化，人民币汇率经 历了多轮转变并进入到贬值轨道。而在1997年亚洲经济危机之中, 中国在人民币政策方面开 始紧盯美元，在2005年至2010年之间，人民汇率经历第一次改革后进入到升值轨道，2010年6 月，人民币汇率制度的第二次改革使得汇率的弹性持续增强，人民币升值现象得到了明确， 
并且有效地维持在一定区间之内。

\section{3. 出口投资商的主要投资方式}

出口投资商主要以国外市场为主要投资对象和投资目标，投资商不仅仅会在国内展开商 品生产和投资, 同时也会在国外展开全面的投入, 进而获取更加广泛的国际市场、技术和资 源等等，这也使得出口投资商的投资方式日益呈现多元化态势。

表1. 出口投资商的主要投资方式

\begin{tabular}{|l|l|l|l|}
\hline 国内投资 & 主要特点 & 国外投资 & 主要特点 \\
\hline 生产投资 & 独立建厂, 投资周期 & 跨国并购 & 当地企业合作, 管理 \\
& 长, 回报稳定, 风险 & & 成熟; 利润回报率 \\
& 偏高, 人工成本低 & & 低, 企业获利快 \\
\hline & 不参与经营, 管理参 & 新建投资 & 投资周期长, 独立控 \\
& 与度不高, 资金优 & & 股; 技术优势, 垄断 \\
& 势, 利润回报较快 & & 地位, 风险抵御能力 \\
& & 强 \\
\hline
\end{tabular}

由上表可以看出，投资商的不同投资方式存在不同的特点，在优势和劣势方面存在比较 明显的差异性。因此投资商要根据外部环境及企业自身状况做出最恰当的投资决策, 有效保 证投资决策的有效性，降低投资风险。

\section{4. 人民币升值下出口投资商决策的影响}

随着全球经济一体化趋势的持续向前, 各项生产要素的流动性逐渐增强, 资本流动的自 由度也在不断提高，这就使得投资商对于投资回报率及投资风险保持更高关注度，当前虽然 部分发达国家对出口投资保持了抵制和消极的态度, 但是经济全球化已经成为经济发展的必 然潮流，人民币升值给我国出口投资商带来了巨大挑战，但同时也给这些企业带来了宝贵的 机遇。出口投资商应该在充分考虑人民币升值带来的影响后做出正确的投资决策。

\section{1 影响投资积极性，可能出现外汇短缺}

人民币升值在一定程度上影响到出口投资商的投资积极性, 导致这种现象的主要原因是 我国产品在对外出口过程中的竞争力会有所下降, 而特别是一些跨国企业和大型企业会将人 民币升值所带来的风险进行转移, 这就使得中小企业面临的压力与风险持续增加, 很多出口 投资商的投资积极性持续下降。另外投资者在向外扩张过程中需要更多的资金支出, 而我国 的外汇管理制度也使得很多企业的外汇出现短缺, 影响到投资行为的顺利进行。

\section{2影响投资者投资条件，同时影响投资效应}

根据相关数据分析模型能够发现, 汇率变化对于低成本价格加成企业的影响更加明显, 这是因为这些企业的定价能力较弱, 边际成本更容易受到外部环境影响。因此人民币升值对 这部分投资者的投资行为会产生非常明显的影响，特别是中小投资者的成本变化比较明显。 另外出口商投资效应也会受到影响, 国际贸易风险持续增加, 企业产品的竞争力减弱, 最终 出现明显的负面投资效应。

\section{3 加大走出去步伐, 实现产业转型}

人民币的升值使得人民币购买力得到了有效提升，出口投资商在对外投资过程中的投资 成本得到了有效降低, 这也为为我国企业走出国内市场, 进军国际市场奠定了坚实的基础。 
我国企业在改革开发后的发展中取得了巨大的发展成就，但是我国企业在管理、技术、资源 等方面仍然与发达国家存在一定差距, 出口投资商应该积极利用人民币升值的机会执行走出 去战略, 有效借鉴并吸收成熟经验, 推动我国企业实现转型升级, 进而提升中国企业在国际 竞争中的核心竞争力。

\section{5. 结束语}

人民币升值对我国出口商投资决策产生了非常明显的影响，其中既有积极影响，同样也 有消极影响，广大投资商应该仅仅把握机遇，提升投资有效性和准确性，降低投资风险，推 动企业的转型升级, 实现跨越式发展。

\section{References}

1. Border region panel evidence on PPP deviations $[\mathrm{J}]$. ThomasM. Fullerton,AndréVarella Mollick. Applied Economics . 2013 (16)

2. A PANEL DATA APPROACH TO THE BEHAVIOURAL EQUILIBRIUM EXCHANGE RATE OF THE ZAR[J] . AndreaSaayman. South African Journal of Economics . 2010 (1)

3. " Issues for Renminbi Internationalization:An Overview". Eichengreen B,Kawai M. Ssrn Electronic Journal . 2014

4. Interactions between CNY and CNH Money and Forward Exchange Markets. Leung D W Y,Fu J. Ssrn Electronic Journal . 2014

5. Exchange Rate Volatility and the Timing of Foreign Direct Investment: Market-Seeking versus Export-Substituting[J] . Chia-ChingLin,Kun-MingChen,Hsiu-HuaRau. Review of Development Economics . 2010 (3)

6. The endogeneity of the exchange rate as a determinant of FDI: A model of entry and multinational firms $[\mathrm{J}]$. Katheryn Niles Russ. Journal of International Economics . 2006 (2)

7. Estimating models of complex FDI: Are there third-country effects?[J] . Badi H. Baltagi,Peter Egger,Michael Pfaffermayr. Journal of Econometrics . 2006 (1)

8. Exchange Rate Uncertainty, Sociopolitical Instability and Private Investment: Empirical Evidence from Latin America[J] . MonicaEscaleras,Dimitrios D.Thomakos. Review of Development Economics . 2007 (2)

9. A model of industrial hollowing-out of neighboring countries by the economic growth of China[J] . Yong Jin Kim. China Economic Review . 2006 (2)

10. Globalisation, multinationals and productivity in Japan's lost decade[J] . Richard Kneller,Danny McGowan,Tomohiko Inui,Toshiyuki Matsuura. Journal of The Japanese and International Economies . 2012 (1) 